\title{
KINEMATIC STUDY OF THE AIR FLOW PRODUCED BY SOME SPRAYERS USED IN "TENDONE" VINEYARDS
}

\author{
Simone Pascuzzi, Anna Guarella
}

\section{Introduction}

The distribution of the pesticides on the target depends largely on the characteristics of the airflow both using pneumatic sprayers and traditional air blast sprayers $[1,6]$.

In order to this a large number of theoretical and experimental studies, regarding the behaviour of the airflow getting out of the diffuser and moving in the environment which is more or less free of obstacles due to the absence / presence of vegetation [2, 5], allowed to explain the various aspects connected to the airflow (decay of velocity in relation to the distance $[4,8]$, interactions with the surrounding air, within the vegetation $[3,10])$.

Nevertheless the operating behaviour of the different sprayers turn out fundamentally unforeseeable, owing to different structural elements and functional parameters $[9,11]$ :

- fan: type, size, technical characteristic, number and angle of impeller blades, number and position of the deflectors plates or, if present, of the counterrotating impeller;

- location and size of the suction devices;

- channels in the fan housing (internal deflectors);

- rotating speed of the air impeller; travel velocity of the sprayer; velocity and direction of the wind.

With this in mind, the Mechanical Section of the PRO.GE.SA. Department of University of Bari carried out a computerized measuring system to study the velocity of the airflow produced by three different air blast spray machines, commonly used for treatments in tendone vineyards in the Abruzzo region. The results of these experimental trials are reported below.

Paper received 19.07.2006; accepted 18.07.2008

Simone PascuZzi, associate professor, Pro.Ge.S.A. Department University of Bari; ANNA GuARELlA, PhD, P.A. Department - University of Bari.

Each of the authors contributed in equal parts to this work.

\section{Materials and methods}

A computerized measuring system to analyse the vector field of the air velocities in a volume (hereafter called reference volume) surrounding the fan of air assisted sprayers usually used in tendone vineyards was designed and built.

On the base of the typical geometric characteristics of the above-mentioned tendone vineyards (inter-row width of $2.3 \div 2.5 \mathrm{~m}$; vegetative horizontal plane placed at $1.8 \div 2 \mathrm{~m}$ from the ground) a reference volume (Fig. 1) of depth $1.20 \mathrm{~m}$ was determined as follows: on the lower side by an horizontal plane placed at $40 \mathrm{~cm}$ from the ground; on the upper side by an horizontal plane placed at $2.00 \mathrm{~m}$ from the ground; at the sides by two vertical planes equidistant from the vertical symmetry plane of the sprayer $(1.30 \mathrm{~m})$.

In a determined points grid within the reference volume, the three perpendicular components of the airflow velocity were evaluated using an ultrasonic anemometer connected to a positioning system, carried out with three sliding rods placed perpendicularly.

A coordinate system was determined as follows:

- axis $z$ - upward, passing through the middle of the air impeller, lying in its plane;

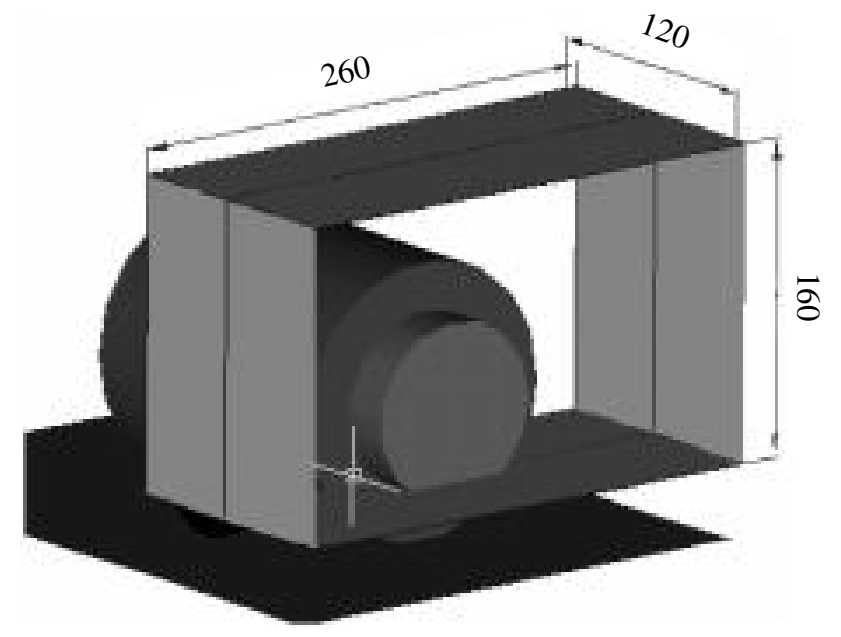

Fig. 1 - Analyzed volume (sizes in $\mathrm{cm}$ ). 
- axis $y$-directed towards the tractor, determined by the intersection between the vertical plane of symmetry of the sprayer and the ground;

- axis $x$-directed towards the right looking from the back of the sprayer, determined by the intersection between the vertical impeller plane and the ground. The evaluation of the three perpendicular vectorial components of the air velocity was made using a Gill Instruments Limited 'Windmaster' ultrasonic anemometer, with the following main technical specifications:

- measure range: $0-45 \mathrm{~m} / \mathrm{s}$;

- measure resolution: $0.01 \mathrm{~m} / \mathrm{s}$;

- measure accuracy: $1.5 \%$

- direction range: $0-359^{\circ}$

- direction resolution: $1^{\circ}$

- direction accuracy: $2^{\circ}$

Some vertical planes parallel to the impeller plane and on each of them a set of $20 \mathrm{~cm}$ equidistant points were considered for the geometric references of the points grid (Fig. 2).

The authors carried out a suitable MATLAB software to generate automatically three-dimensional graphics of the velocity field measured by the instrument.

The testing was made under cover, using the same

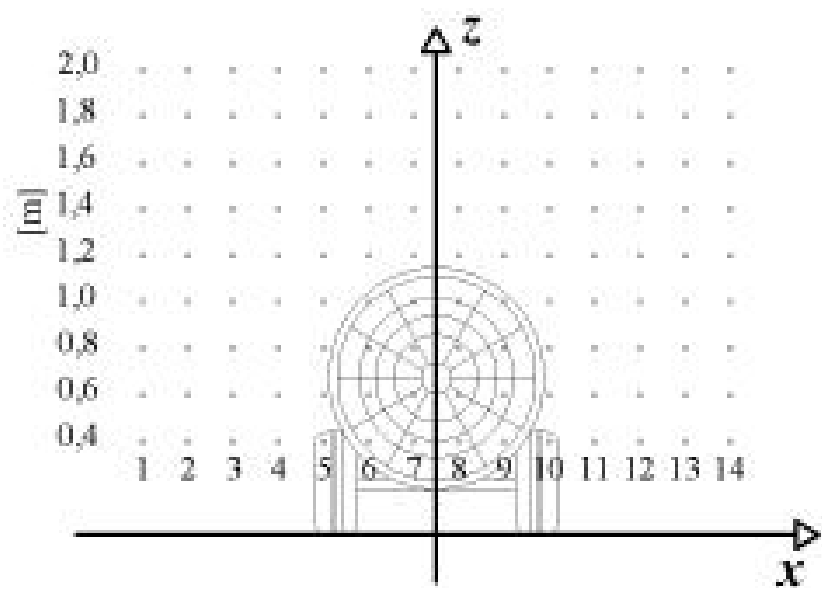

Fig. 2 - Points grid considered for the measure of the air velocity. tractor operating at $540 \mathrm{rpm}$ of its power takeoff.

The air velocity vectors evaluation concerned three different air blast sprayers:

1 -GNAGNANELLA "NBC 1000" traditional airconvection sprayer equipped with axial ventilator, having these main specifications (Fig. 3a): impeller nominal diameter: $800 \mathrm{~mm}$; intake diameter (external side): $900 \mathrm{~mm}$; distance between the ground and the centre of impeller: $740 \mathrm{~mm}$; airflow rate (measured at trial velocity): $34000 \mathrm{~m}^{3} / \mathrm{h}$;

2 -NOBILI "Oktopus mini” air blast sprayer equipped with a pressure-driven atomizing mechanism and a centrifugal fan, with (Fig. 3b): impeller nominal diameter: $400 \mathrm{~mm}$; intake diameter: $400 \mathrm{~mm}$; distance between the ground and the centre of impeller: $750 \mathrm{~mm}$; airflow rate (measured at trial velocity): $20000 \mathrm{~m}^{3} / \mathrm{h}$;

3 -SALERNO "D'Alicandro" pneumatic sprayer with the following specifications: (Fig 3c): impeller nominal diameter: $185 \mathrm{~mm}$; intake diameter: 280 $\mathrm{mm}$; distance between the ground and the centre of impeller: $750 \mathrm{~mm}$; airflow rate (measured at trial velocity): $2170 \mathrm{~m}^{3} / \mathrm{h}$.

\section{Results and discussion}

The airflow produced by fan of the traditional airconvection sprayer (GNAGNARELLA “NBC 1000”) gave rise to interferences in all the reference volume and turned out to be in excess regarding the tendone vineyards that mostly need of airflow upward directed (Fig. 4a). This sprayer, moreover, was equipped with deflector plates to adjust the torsion produced by the axial impeller. The diagram shows that these deflector plates really produced an adjustment of the fluid paths, even though caused an energy absorption and an intensity reduction.

In the diagram of Fig. $4 a$ and those following the position of the fan is indicated.

Fig. $4 b$ points out an asymmetry of the airflow pattern on leaving the fan and, moreover, the intake air flow paths.
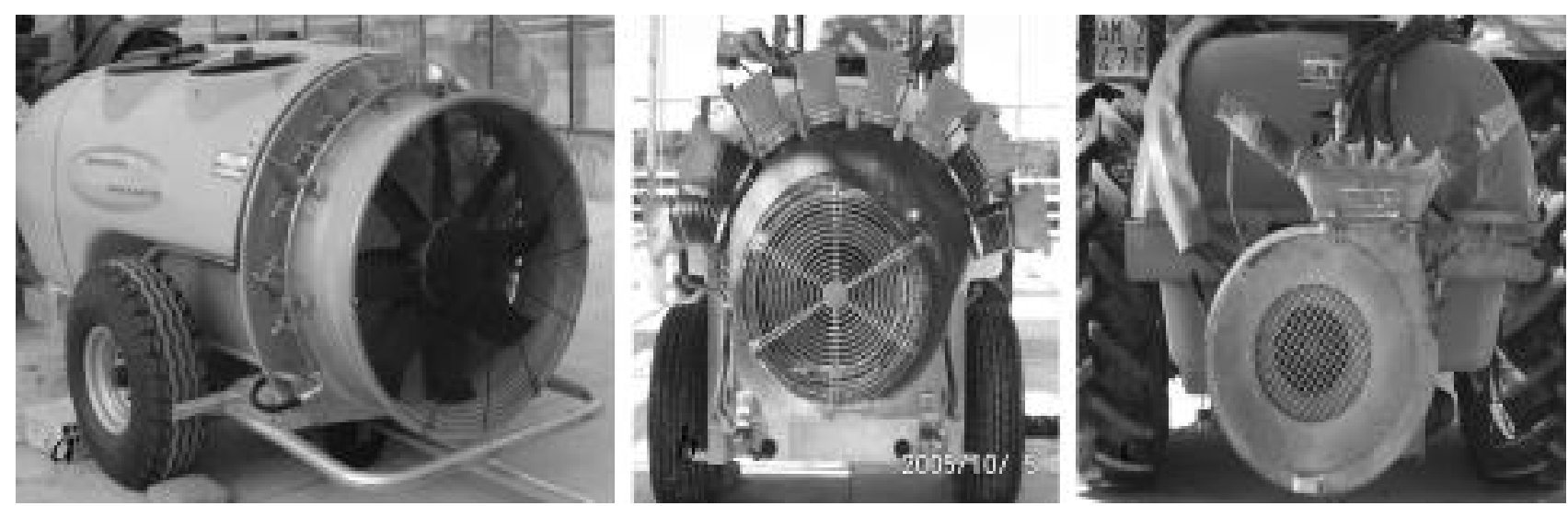

Fig. 3 - (a): GNAGNARELLA “NBC 1000" traditional air-convection sprayer; $(b)$ : NOBILI “Oktopus mini” air blast sprayer; $(c)$ : SALERNO "D'Alicandro" pneumatic sprayer. 

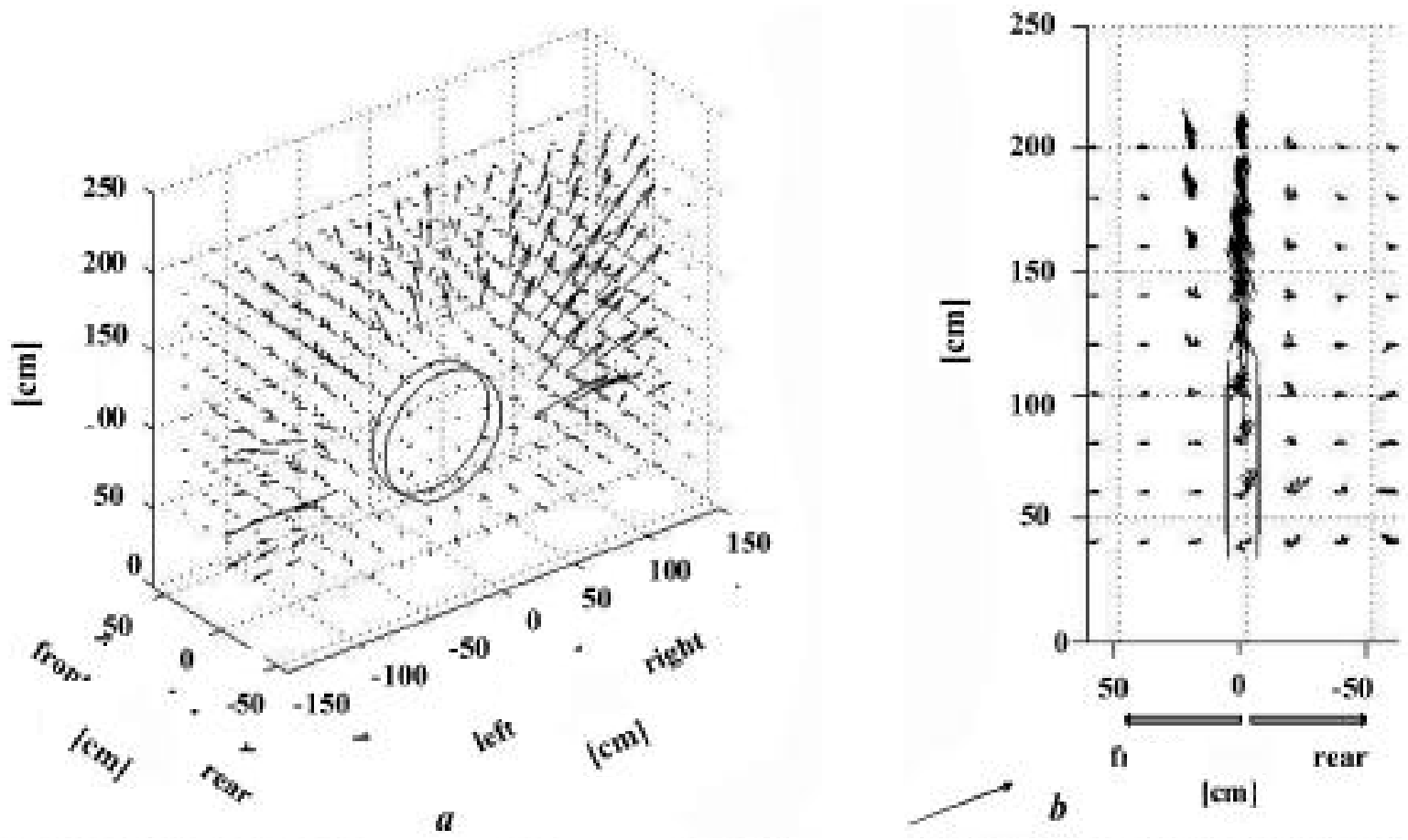

Fig. 4 - GNAGNARELLA "NBC 1000" sprayer - $(a)$ : Axonometric projection of all air velocity vectors in the space surroundings the fan; $(b)$ : Projection of all air velocity vectors, registered at different depths and heights, on a single vertical plane, parallel to the rotation axis of the fan (sizes in $\mathrm{cm}$ ).

The diagrams of Fig. 5 display the available flow or that which reached the vegetative and productive area, placed in a horizontal position respectively at $1.8 \mathrm{~m}$ (Fig. 5a) and $2.0 \mathrm{~m}$ (Fig. 5b) from the ground plane.

These graphics prove that the airflow velocity was not uniform in the cross section of the inter-row where the sprayer travels and quickly reduced itself going on from a ground height of $1.8 \mathrm{~m}$ to $2.0 \mathrm{~m}$.
Furthermore, the deflectors plates produced the airflow velocity reduction proceeding from right to left and the nozzles gave rise to the peaks.

The NOBILI "Oktopus mini", according to the manufacturer, is a suitably designed air blast sprayer for treatments in tendone vineyards. The fan-shaped diffusers each one with a nozzle holder group, however, produced an airflow directionally like that of traditional air-convection air blast sprayer (Fig. 6a). The centrifigal air impeller caused the more elevated values of velocity vectors (Fig. 6a).
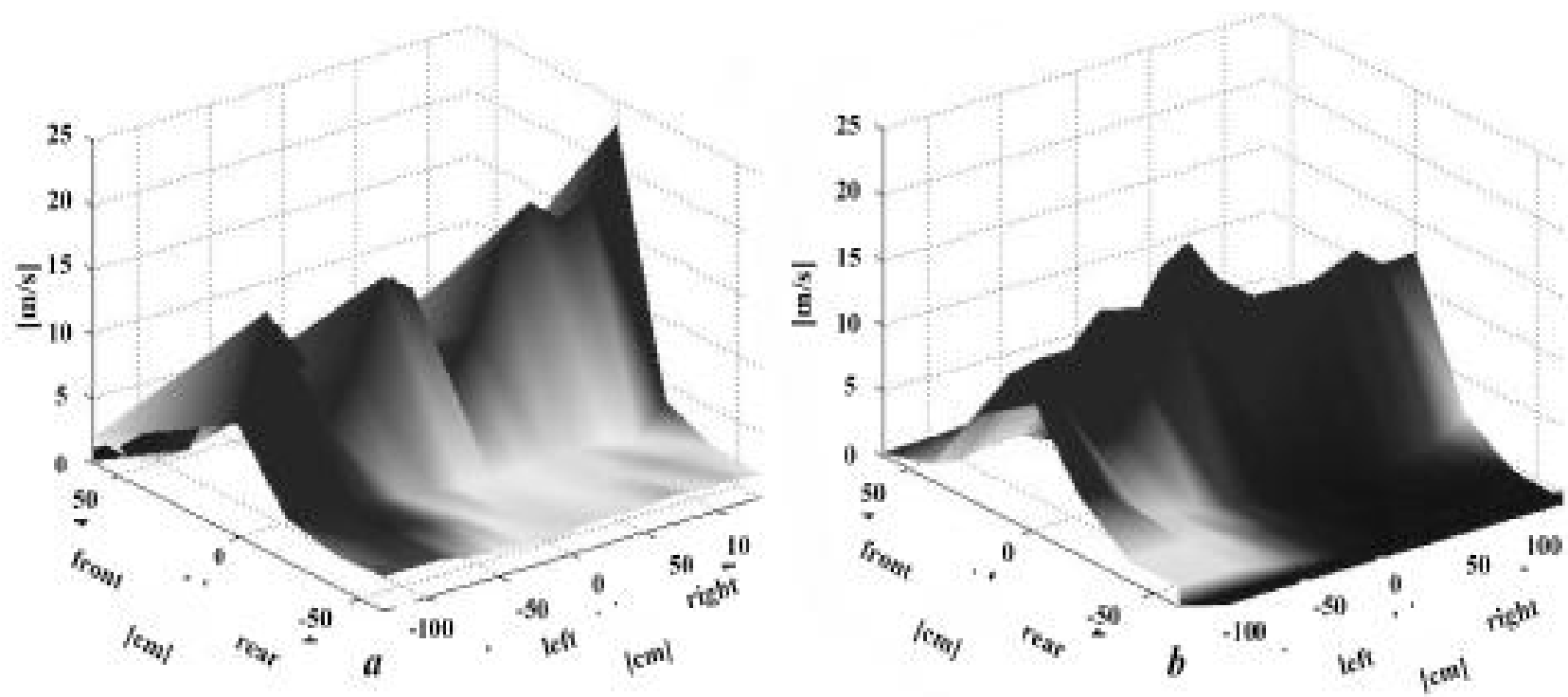

Fig. 5 - GNAGNARELLA "NBC 1000" sprayer - $(a)$ : Air velocity measured in a horiontal points grid, placed at $1.8 \mathrm{~m}$ from the ground plane; $(b)$ : Air velocity measured in a horiontal points grid, placed at $2.0 \mathrm{~m}$ from the ground plane. 

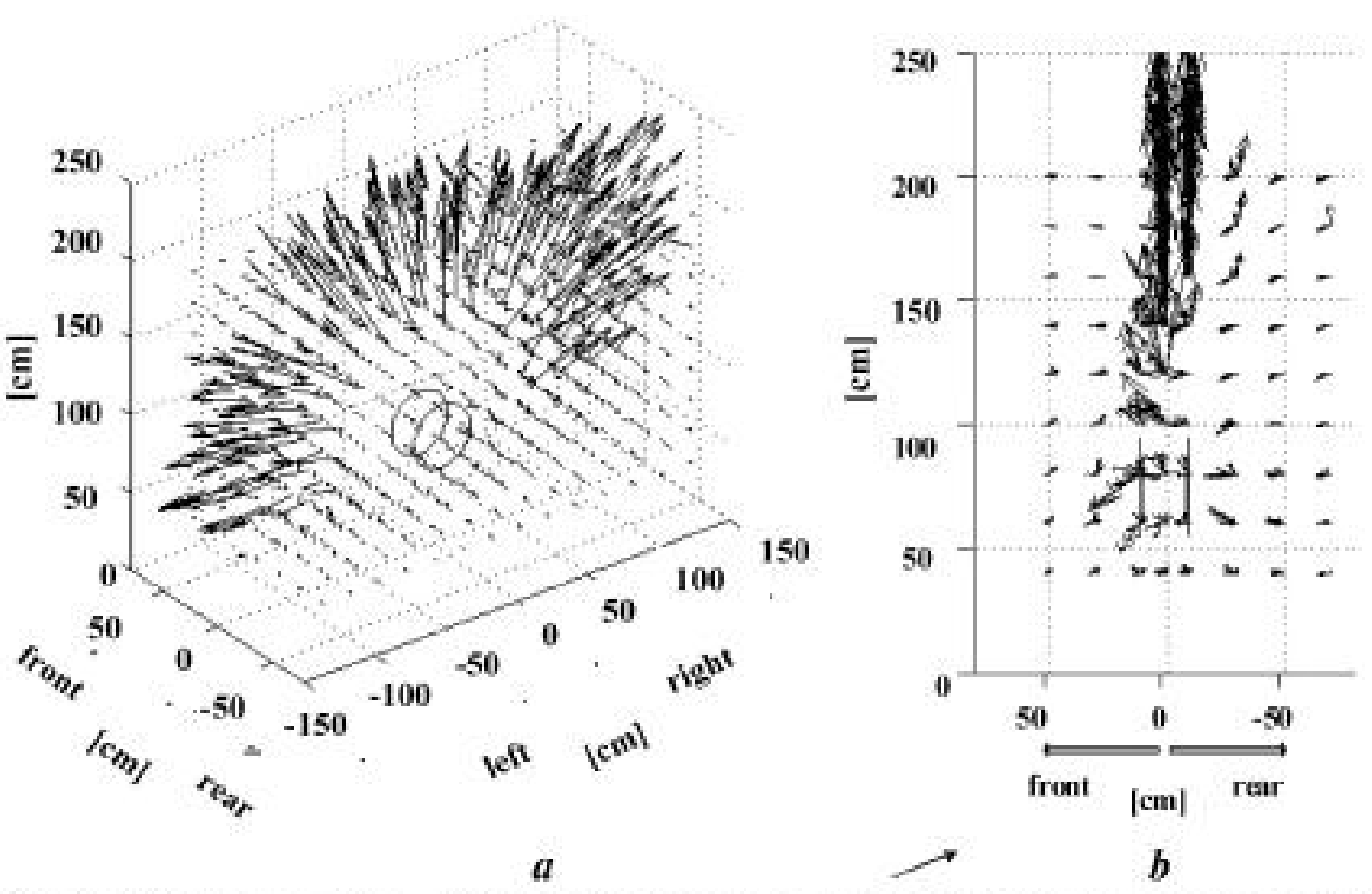

Fig. 6 - NOBILI "Oktopus mini”" sprayer - $(a)$ : Axonometric projection of all air velocity vectors in the space surroundings the fan; $(b)$ : Projection of all air velocity vectors, registered at different depths and heights, on a single vertical plane, parallel to the rotation axis of the fan.

In case of treatments of all the rows, the canopy of the tendone vineyards is not reached by the airflow coming out of the side diffusers; but these diffusers are suitable for treatments to the branches.

Fig. $6 b$ points out the symmetrical airflow pattern on leaving the fan and the intake air flow paths.

As known, the casing collects the air which exits the outer circumference of the impeller allowing it to expand to reduce the velocity of the flow and convert kinetic energy into static pressure. Therefore the air flow which exited through the discharge diffusers placed on the casing was not in the cross section of the inter-row at respectively ground heights of $1.8 \mathrm{~m}$ and $2.0 \mathrm{~m}$ uniformly distributed and the air velocities rose going on from right to left (Fig. $7 a$ and Fig 7b). In these diagrams, the crests can be produced by the presence of the discharge diffusers which caused a discontinuity in the airflow rate.

The SALERNO "D'Alicandro" is a suitably designed pneumatic sprayer for treatments on tendone vineyards. In fact, the predominant air flow was directed towards the top of the vines and the side one was considerably reduced. Probably, this allowed a reduction in size of the fan and its performances (air flow rate, speed) (Fig. 8a).
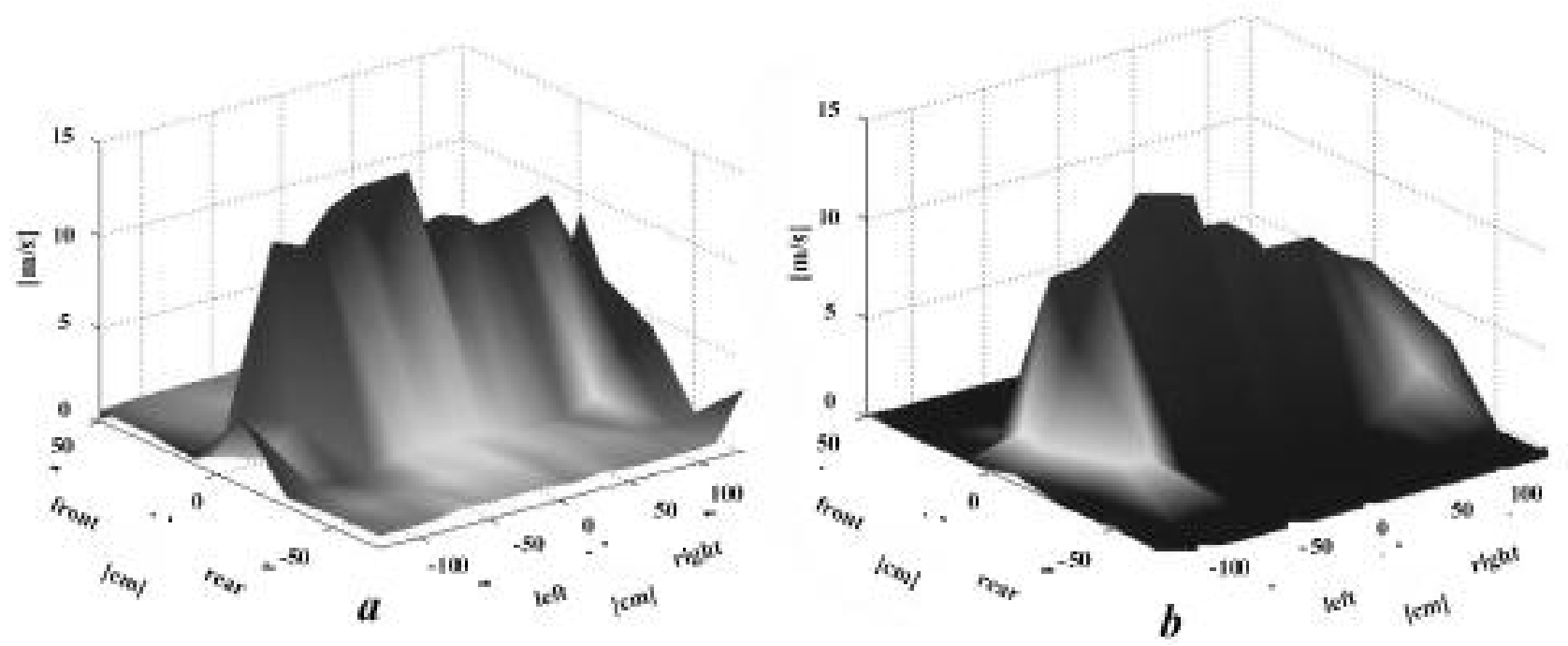

Fig. 7 - NOBILI "Oktopus mini" sprayer - (a): Air velocity measured in a horiontal points grid, placed at $1.8 \mathrm{~m}$ from the ground plane; $(b)$ : Air velocity measured in a horiontal points grid, placed at $2.0 \mathrm{~m}$ from the ground plane. 

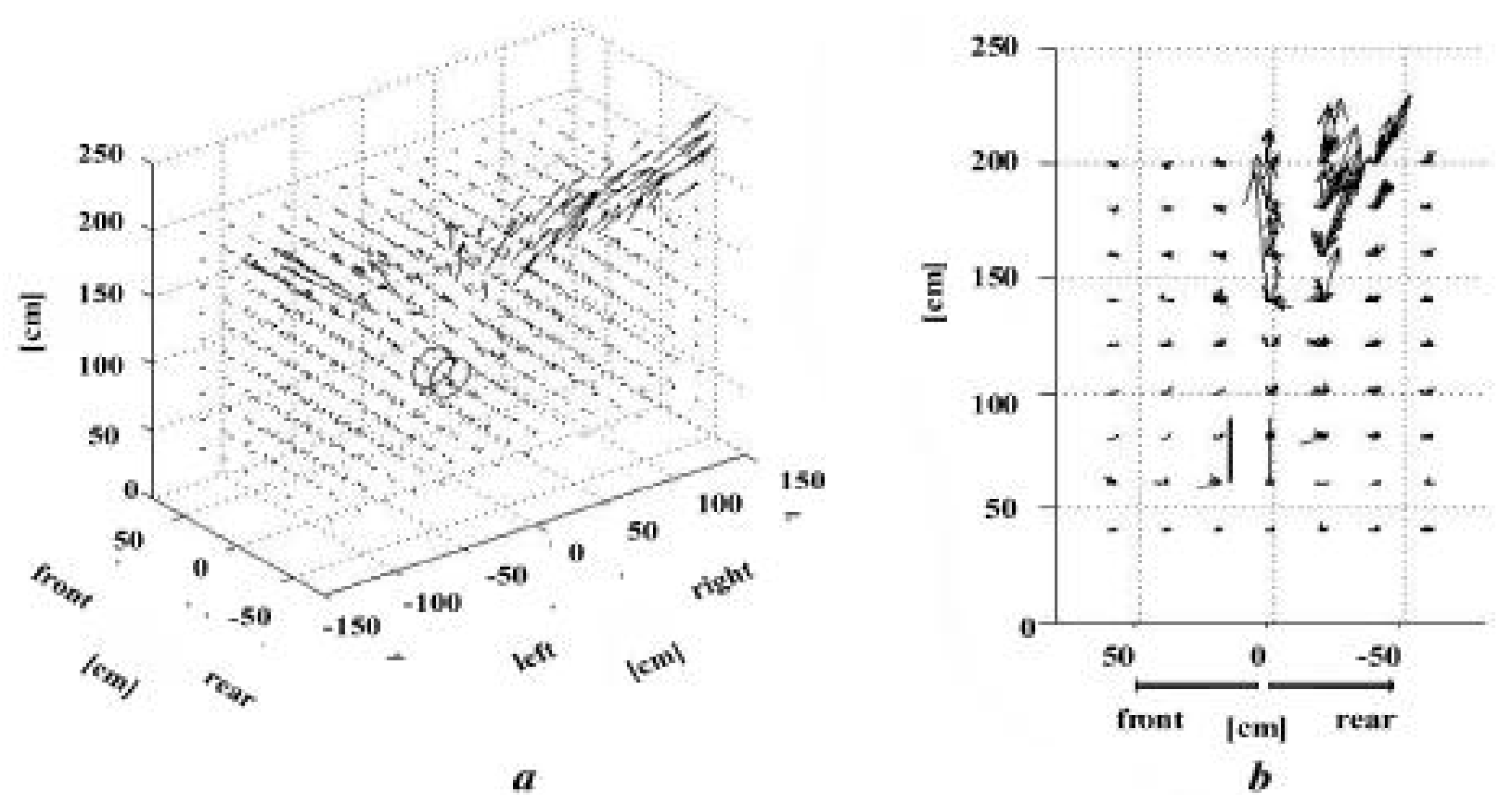

Fig. 8 - SALERNO "D'Alicandro" pneumatic sprayer - $(a)$ : Axonometric projection of all air velocity vectors in the space surroundings the fan; (b): Projection of all air velocity vectors, registered at different depths and heights, on a single vertical plane, parallel to the rotation axis of the fan.

The air flow, clearly asymmetrical, was of directed towards the back of the machine (Fig. $8 b$ ).

The diagrams of Fig. 9, that show the air flow at the transversal planes, placed at heights from the ground of $1.80 \mathrm{~m}$ (Fig. 9a) and $2.00 \mathrm{~m}$ (Fig. 9b) respectively, highlight the performance of the air flow aimed at the target. It should be stressed, however, that the geometry of the diffusers could be improved, to make the upward flow more symmetrical.

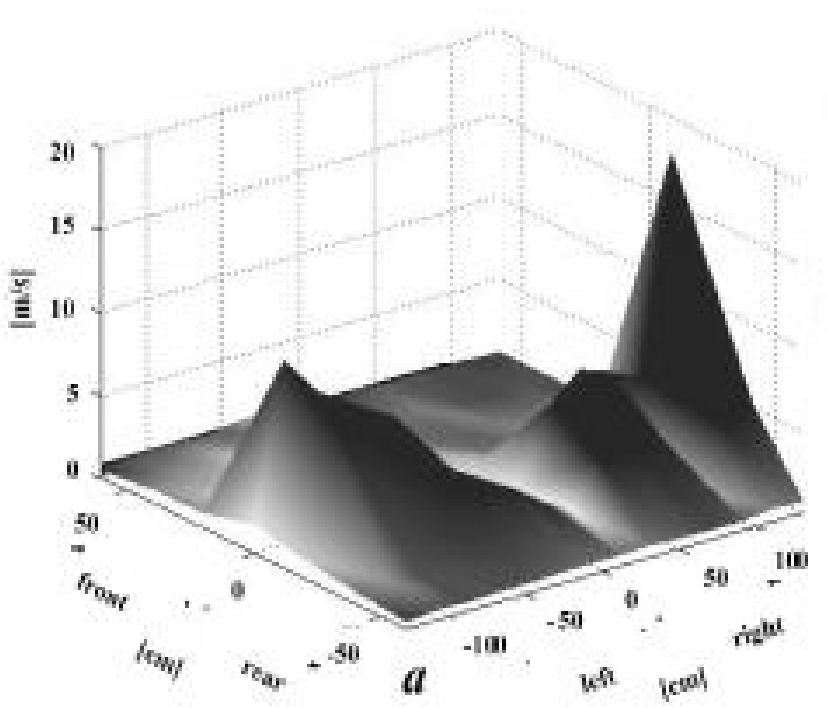

\section{Conclusions}

The research carried out has looked for:

- to assess the effectiveness of the method formula including the measuring instrument used;

- to calibrate a software suitable for the measured kinematic data acquisition, elaboration and representation;

- to test the performance of three different sprayers: the first, a traditional air-convection air blast sprayer, the other two, suitably designed for treatments in tendone vineyards.

Fig. 9 - SALERNO "D'Alicandro" pneumatic sprayer - $(a)$ : Air velocity measured in a horiontal points grid, placed at $1.8 \mathrm{~m}$ from the ground plane; $(b)$ : Air velocity measured in a horiontal points grid, placed at $2.0 \mathrm{~m}$ from the ground plane. 
The obtained results have allowed to explain some aspects regarding:

- the interferences, with still sprayers in cover environments, between the fan-diffusers group and the surrounding air included in an ideal parallelepiped $1.20 \mathrm{~m}$ thick with section equal to an average interrow of tendone;

- the rough evaluation of the efficacy of the fan-diffusers group and of the useful air flow for treatments;

- the distribution on the target of the registered air velocity vectors, useful for the transport and penetration into the vegetation of the chemicals being distributed.

The pointed out interferences regarded all the ideal parallelepiped volume investigated, with different degree depending on the sprayer under test.

The intensity and direction of the vectors, at the various heights from ground level and at different distances from the fan-diffusers, showed some features common to the three sprayers tested.

The air flow and fan produced, according to specific modes, sucked air from the surrounding environment, which was analysed during the research. In particular, the air flow which exited through the discharge diffusers and moving towards the target, as expected both in theory [10] and experiment [7], sucked air from the surrounding environment that enlarged the total air volume and, therefore, the flow rate on the target. This air flow reaches $40-60 \mathrm{~cm}$ thick near the target, in relation to the distance from the diffusers and the flow rate and speed at the air outlet.

The impeller, especially the air inlet side, produced an sucked air from the surrounding environment; this is verified by the velocity vectors placed near the fan in the graphics, that converge towards the air inlet. Moreover, the sucked air coming from the zone included between the ground level and the impeller rotation axis, produced the conveying of impurities of the ground.

Useful air is only that which reaches the target. In order to this the air convection sprayer and the sprayer equipped with the fan-shaped diffusers behaved clearly differently to the pneumatic type. The first two, though more adaptable, are less effective than the third, because of the side air flows which reach not the target of the tendone vines.

\section{Acknowledgements}

This research was funded by the Regional Agency for Service of Agricultural Development (A.R.S.S.A.) from Abruzzi (dott. A. Ricci). Special thanks to p.a. D. Civitella of Consortium for the irrigation techniques (Co.T.Ir.) from Abruzzi and to C. Gidiuli, V. Marzano D. Sfregola of the PRO.GE.S.A. Department for the availability and commitment showed in conducting the experimental tests.

\section{References}

[1] Bernacki H. et Al., Agricultural Machines, theory and construction, vol. I, U.S. Departement of Agriculture and the National Science Foundation, Washington D.C., (1972), 812-821.

[2] Brazee R.D. ET AL., Turbulent jet theory applied to air sprayers, Transaction of the ASAE, 1981,24(2), 266-272.

[3] Delete M.A. ET Al., CFD prototyping of an air-assisted orchard sprayer aimed at drift reduction, Computers and Electronics in Agriculture, 2007,vol.55(1), 16-27.

[4] FRISO D., Una equazione per la determinazione del deceleramento attraverso la vegetazione della corrente d'aria prodotta da irroratrici per colture arboree, Riv. di Ing. Agr. (1994), 4, 200-208.

[5] GiLES D.K. ET AL., Turbulent jet flow characteristics of a dual-port, air-atomization spray nozzle, J. agric. eng. res, 1991, vol. 49, n² 2 133-149.

[6] LANDERs A.J., Airblast sprayers, Encyclopedia of Pest Management, D. Pimental, New York: Marcel Dekker Inc, 11-13.

[7] TAMAgnone M., I criteri di scelta dei volumi d'aria, Atti del Convegno " Nuovi criteri di regolazione delle macchine irroratrici per i trattamenti al vigneto", UNACOMA SERVICE, Roma, 46-53.

[8] Reichard D.L. ET Al., Air velocities delivered by orchard air sprayers, Transaction of the ASAE , 1979, 22 (1), 69-74.

[9] Sidahmed M.M., Brown R.B., Simulation of spray dispersal and deposition from a forestry airblast sprayer - Part I: Air jet model, Transaction of the ASAE, 2001, vol. 44, nº 1, 5-10.

[10] VIERI M., VentuRI A., Una procedura informatica per il controllo del comportamento delle gocce nella irrorazione con atomizzatori, Rivista di Ingegneria Agraria, 2001, 4 (11), 225-235.

[11] Xu Z.G. ET AL., Stochastic modelling of turbulent spray dispersion in the near-field of orchard sprayers, Journal of Wind Engineering and Industrial Aerodynamics, 1998, 74-76, 295-304.

\section{SUMMARY}

A computerized measuring system to analyse the vector field of the air velocities in a volume surrounding the fan of air assisted sprayers usually used in tendone vineyards was designed and built.

The performance of three different sprayers was tested: the first, a traditional air-convection sprayer, the other two, suitably designed for treatments in tendone vineyards.

The air flow which exited through the discharge diffusers and moving towards the target sucked air from the surrounding environment that enlarged the flow rate on the target.

The available flow was that which reached the vegetative and productive area, placed in a horizontal position respectively at $1.8 \mathrm{~m}$ and $2.0 \mathrm{~m}$ from the ground plane. The pneumatic sprayer produced an air flow clearly directed towards the top of the vines.

\section{Key words:}

Sprayers, impeller, air velocity, "Tendone" trained vineyard. 